\author{
Andrew I. R. Maas \\ Giuseppe Citerio
}

\section{Noninvasive monitoring of cerebral oxygenation in traumatic brain injury: a mix of doubts and hope}

Received: 28 April 2010

Accepted: 29 April 2010

Published online: 26 May 2010

(C) Copyright jointly held by Springer and ESICM 2010

\author{
A. I. R. Maas (-) \\ Department of Neurosurgery, University Hospital Antwerp, \\ Wilrijkstraat 10, 2650 Edegem, Belgium \\ e-mail: andrew.maas@uza.be \\ Tel.: +32-3-8214537 \\ Fax: $+32-3-8252428$ \\ G. Citerio \\ Neuroanesthesia and Neurosurgical Intensive Care Unit, \\ Department of Perioperative Medicine and Intensive Care, \\ San Gerardo Hospital, Monza, Italy
}

Three mainstays of the medical treatment of patients with traumatic brain injury (TBI) are to control raised intracranial pressure (ICP) and to maintain cerebral perfusion pressure (CPP) and cerebral oxygenation within normal ranges [1]. Consequently, monitoring of these parameters in neurocritical care is indicated.

Nowadays, ICP is routinely monitored in patients with severe TBI, and CPP is calculated as the difference between mean arterial blood pressure and ICP. The revised Guidelines for the Management of Severe TBI advocate (class III evidence) monitoring of cerebral oxygenation by jugular oximetry or measurement of brain tissue oxygen pressure via a parenchymal probe [2]. Jugular oximetry provides a more global estimate of oxygen extraction by the brain, whilst brain tissue oxygen monitoring represents a very local measurement, averaging the oxygen tension in a relatively small volume of tissue. Both techniques are widely accepted in clinical practice [3] and support management in TBI, but carry the disadvantage of being invasive [4]. More ideal would be noninvasive measurements of cerebral oxygenation. In this regard, near-infrared spectroscopy (NIRS) offers hope.

Basically, in NIRS, light generated at specific wavelengths is transmitted through the scalp into the brain, and changes in the light attenuation at the receiving end of the reflected (or transmitted) light are converted via a computer algorithm into changes in chromophore concentration [5]. As light within the visible spectrum does not penetrate tissue more than approximately $1 \mathrm{~cm}$, wavelengths in the near-infrared region between 650 and $900 \mathrm{~nm}$ are used, permitting deeper penetration. Within these ranges, oxyhemoglobin $\left(\mathrm{HbO}_{2}\right)$, deoxyhemoglobin $(\mathrm{Hb})$, and oxidized cytochrome oxidase (CytOx) have characteristic absorption spectra [6]. In contrast to pulse oximetry, in which only the arterial component is considered, NIRS captures an average of the arterial, capillary, and venous compartments. Various assumptions are made in the calculation algorithm of cerebral oxygen saturation with NIRS, which may not always be valid, and uncertainty exists regarding whether NIRS, as claimed, mainly measures the intracranial compartment or also the extracranial compartment. Translation of NIRS systems and methods into the clinical field requires an understanding of the physiologic basis of the measured NIRS signals, and unfortunately some uncertainly still remains.

Dunn et al. [7] studied NIRS to evaluate cerebral oxygenation status and adequacy. They concluded that determination of accurate reference ranges for normal subjects or ischemic thresholds is not easy. One reason for this might be the significant baseline variability of NIRS: the "normal" range varies between $60 \%$ and $75 \%$, with a coefficient of variation for absolute baseline values of almost $10 \%$. Moreover, the lack of standardization of currently available NIRS devices also contributes to the difficulty in defining thresholds. 
The main clinical applications are in neonatology $[8$, 9], in which case the head can be transilluminated, and in coronary or carotid artery surgery [10-18]. Few studies have been published on use of NIRS in TBI $[19,20]$, and the technique has not yet been convincingly validated for the indication TBI by comparison with other measures of cerebral oxygenation. Recently, Kim et al. [19] compared continuous bedside NIRS/diffuse correlation spectroscopy (DCS) with xenon computed tomography (XeCT) measurements in a small cohort of neurocritical patients (aneurysmal subarachnoid hemorrhage, TBI, and ischemic stroke) in whom interventions aimed at altering cerebral blood flow (CBF) were applied. Regional CBF measured with DCS correlated with $\mathrm{CBF}$ measured by $\mathrm{XeCT}$ in coregistered spatial regions of the injured brain, and correlations were found between $\mathrm{CBF}$ measured by both techniques and NIRS parameters.

In this issue of Intensive Care Medicine, Leal-Noval et al. [21] report on a well-conducted prospective observational study investigating the relation between noninvasive regional transcranial oxygen saturation $\left(\mathrm{rSO}_{2}\right)$ obtained by NIRS technique and invasive measurements of brain tissue oxygen tension $\left(\mathrm{PbrO}_{2}\right)$, performed with the Licox device, in 22 patients with severe TBI over a $16 \mathrm{~h}$ monitoring period. Although a significant relation between $\mathrm{rSO}_{2}$ and $\mathrm{PbrO}_{2}$ was confirmed, the authors report low accuracy for detecting episodes of moderate cerebral hypoxia, as defined by $\mathrm{PbrO}_{2} \leq 15 \mathrm{mmHg}$. Higher sensitivity and specificity was found at a cutoff value for $\mathrm{PbrO}_{2}$ of $12 \mathrm{mmHg}$, representing more severe cerebral hypoxia. These observations cast further doubts on the potential applicability of NIRS for the indication TBI. It should be recognized, however, that both techniques measure different parameters and that $\mathrm{PbrO}_{2}$ measurements cannot be considered the gold standard for monitoring cerebral oxygenation. NIRS, in principle, measures in the intravascular compartment of the arterial, capillary, and venous beds as it focuses on the chromophores oxyhemoglobin and deoxyhemoglobin. $\mathrm{PbrO}_{2}$ is a measure in the tissue and, in addition to intravascular factors, the diameter of capillaries and diffusion through the tissue are relevant factors contributing to the measured values. Thus, $\mathrm{PbrO}_{2}$ may be more sensitive to tissue hypoxia caused by restricted diffusion due to edema, a particular problem in TBI. A limitation of $\mathrm{PbrO}_{2}$ measurements is that they only capture a small volume of tissue, and results obtained may not be representative of more global oxygenation. The conclusion by the authors that NIRS does not accurately reflect cerebral oxygenation as measured by $\mathrm{PbrO}_{2}$ and should not be considered a substitute for routine $\mathrm{PbrO}_{2}$ monitoring is therefore appropriate.

Whether NIRS has added value or even any value in TBI cannot be directly answered based on this study. Of concern is that $45 \%$ of the original sample size of 56 patients were excluded for reasons specific to TBI or the technology: frontal hematoma, wounds on either the scalp or forehead, or deficient NIRS signal. Subcutaneous swelling or wounds on scalp and forehead are common in TBI patients. Intracranial lesions and/or recent surgery would further prohibit use of the technique. Uncertainty also exists regarding how traumatic subarachnoid hemorrhage may confound the signal.

These factors, specific to TBI, set this disease aside with regard to the applicability of NIRS from other more controlled conditions such as extracranial vascular surgery. A technique that, in TBI, may not be applicable in nearly half of patients would seem of limited value.

A relative weakness of the study by Leal-Noval et al. is that they did not attempt to identify the cause of episodes of low $\mathrm{PbrO}_{2}$. This would have been of interest with regard to the relative contribution of systemic and intracranial causes, specifically directed at the question of whether NIRS detection may be limited to systemic events which could also influence the extracranial compartment. Again, this sets TBI aside from NIRS measurements in extracranial vascular surgery, in which indication all events have a systemic nature. Murkin et al. [22], in a randomized blinded study on 200 patients undergoing coronary bypass surgery, found that monitoring cerebral $\mathrm{rSO}_{2}$ by NIRS permitted earlier detection and treatment of systemic events causing cerebral desaturation. Fewer incidence of major organ dysfunction were found, and duration of intensive care unit (ICU) stay was shorter in the intervention group. The most frequent interventions in this study were increasing mean arterial blood pressure, increasing pump flow, and correction of hypocapnia. Concerns regarding the relative contributions of the extracranial and intracranial compartments to the NIRS signal may be less relevant here. Lam et al. [23], in a study on patients undergoing carotid endoarteriectomy in which sequential clamping of the external and internal carotid artery was performed, found a substantial contribution of the external circulation to the NIRS signal.

Kirkpatrick et al. [24] proposed to adjust for the extracranial contribution by monitoring skin blood flow changes by flowmetry. Further advances in NIRS technology by applying spatially resolved spectroscopy and calculation of the Tissue Oxygen Index have been reported to better target the intracranial compartment [25]. Whether this also holds for TBI is unknown. These approaches were, however, not used in the study by LealNoval et al.

In summary, the study by Leal-Noval et al. strengthens the opinion that NIRS technology may have potential but is not yet ready for routine clinical use for the indication TBI. Technological advances offer hope, and further clinical research should be encouraged. As Alexandre Dumas wrote in The Count of Monte Cristo: "All human wisdom is summed up in these two words: wait and hope." We can modify and actualize this sentence for the NIRS dilemma in TBI as "wait and hope along with research." 


\section{References}

1. Maas AI, Stocchetti N, Bullock R (2008) Moderate and severe traumatic brain injury in adults. Lancet Neurol 7:728-741

2. Bratton SL, Chestnut RM, Ghajar J, McConnell Hammond FF, Harris OA, Hartl R, Manley GT, Nemecek A, Newell DW, Rosenthal G, Schouten J, Shutter L, Timmons SD, Ullman JS, Videtta W, Wilberger JE, Wright DW (2007) Guidelines for the management of severe traumatic brain injury. X. Brain oxygen monitoring and thresholds. J Neurotrauma 24(Suppl 1):S65-S70

3. Andrews PJ, Citerio G, Longhi L, Polderman K, Sahuquillo J, Vajkoczy P (2008) NICEM consensus on neurological monitoring in acute neurological disease. Intensive Care Med 34:1362-1370

4. Bhatia A, Gupta AK (2007) Neuromonitoring in the intensive care unit. II. Cerebral oxygenation monitoring and microdialysis. Intensive Care Med 33:1322-1328

5. Murkin JM, Arango M (2009) Nearinfrared spectroscopy as an index of brain and tissue oxygenation. $\mathrm{Br} \mathrm{J}$ Anaesth 103(Suppl 1):i3-i13

6. Owen-Reece H, Smith M, Elwell CE, Goldstone JC (1999) Near infrared spectroscopy. Br J Anaesth 82:418-426

7. Dunn IF, Ellegala DB, Kim DH, Litvack ZN (2006) Neuromonitoring in neurological critical care. Neurocrit Care 4:83-92

8. Adcock LM, Wafelman LS, Hegemier S, Moise AA, Speer ME, Contant CF, Goddard-Finegold J (1999) Neonatal intensive care applications of nearinfrared spectroscopy. Clin Perinatol 26:893-903, ix

9. Cooper CE, Elwell CE, Meek JH, Matcher SJ, Wyatt JS, Cope M, Delpy DT (1996) The noninvasive measurement of absolute cerebral deoxyhemoglobin concentration and mean optical path length in the neonatal brain by second derivative near infrared spectroscopy. Pediatr Res 39:32-38

10. Tanaka E, Chen FY, Flaumenhaft R, Graham GJ, Laurence RG, Frangioni JV (2009) Real-time assessment of cardiac perfusion, coronary angiography, and acute intravascular thrombi using dual-channel nearinfrared fluorescence imaging. J Thorac Cardiovasc Surg 138:133-140
11. Ranucci M, Isgro G, De la Torre T, Romitti F, Conti D, Carlucci C (2008) Near-infrared spectroscopy correlates with continuous superior vena cava oxygen saturation in pediatric cardiac surgery patients. Paediatr Anaesth 18:1163-1169

12. Dullenkopf A, Baulig W, Weiss M, Schmid ER (2007) Cerebral nearinfrared spectroscopy in adult patients after cardiac surgery is not useful for monitoring absolute values but may reflect trends in venous oxygenation under clinical conditions. $\mathbf{J}$

Cardiothorac Vasc Anesth 21:535-539

13. Huang JH, Su ZK, Wang SM (2007)

Near-infrared spectroscopy monitoring of brain oxygen in infant cardiac surgery. Asian Cardiovasc Thorac Ann 15:194-199

14. Tortoriello TA, Stayer SA, Mott AR, McKenzie ED, Fraser CD, Andropoulos DB, Chang AC (2005) A noninvasive estimation of mixed venous oxygen saturation using near-infrared spectroscopy by cerebral oximetry in pediatric cardiac surgery patients. Paediatr Anaesth 15:495-503

15. Hayashida M, Kin N, Tomioka T, Orii $\mathrm{R}$, Sekiyama H, Usui $\mathrm{H}$, Chinzei M, Hanaoka K (2004) Cerebral ischaemia during cardiac surgery in children detected by combined monitoring of BIS and near-infrared spectroscopy. $\mathrm{Br}$ J Anaesth 92:662-669

16. Nollert G, Jonas RA, Reichart B (2000) Optimizing cerebral oxygenation during cardiac surgery: a review of experimental and clinical investigations with near infrared spectrophotometry. Thorac Cardiovasc Surg 48:247-253

17. Daubeney PE, Smith DC, Pilkington SN, Lamb RK, Monro JL, Tsang VT, Livesey SA, Webber SA (1998) Cerebral oxygenation during paediatric cardiac surgery: identification of vulnerable periods using near infrared spectroscopy. Eur J Cardiothorac Surg 13:370-377

18. Pennekamp CW, Bots ML, Kappelle LJ, Moll FL, de Borst GJ (2009) The value of near-infrared spectroscopy measured cerebral oximetry during carotid endarterectomy in perioperative stroke prevention. A review. Eur J Vasc Endovasc Surg 38:539-545
19. Kim MN, Durduran T, Frangos S, Edlow BL, Buckley EM, Moss HE, Zhou C, Yu G, Choe R, MaloneyWilensky E, Wolf RL, Grady MS, Greenberg JH, Levine JM, Yodh AG, Detre JA, Kofke WA (2010)

Noninvasive measurement of cerebral blood flow and blood oxygenation using near-infrared and diffuse correlation spectroscopies in critically braininjured adults. Neurocrit Care 12:173180

20. Adelson PD, Nemoto E, Colak A, Painter M (1998) The use of near infrared spectroscopy (NIRS) in children after traumatic brain injury: a preliminary report. Acta Neurochir Suppl 71:250-254

21. Leal-Noval S, Cayuela A, Arellano V, Padilla V, Corcia Y, Marin A, GarciaAlfaro C, Amaya R, Murillo-Cabezas F (2010) Invasive and non-invasive assessment of cerebral oxygenation in patients with severe traumatic brain injury. Intensive Care Med. doi: 10.1007/s00134-010-1920-7

22. Murkin JM, Adams SJ, Novick RJ, Quantz M, Bainbridge D, Iglesias I, Cleland A, Schaefer B, Irwin B, Fox S (2007) Monitoring brain oxygen saturation during coronary bypass surgery: a randomized, prospective study. Anesth Analg 104:51-58

23. Lam JM, Smielewski P, al-Rawi P, Griffiths P, Pickard JD, Kirkpatrick PJ (1997) Internal and external carotid contributions to near-infrared spectroscopy during carotid endarterectomy. Stroke 28:906-911

24. Kirkpatrick PJ, Smielewski P, Al-Rawi P, Czosnyka M (1998) Resolving extraand intracranial signal changes during adult near infrared spectroscopy. Neurol Res 20(Suppl 1):S19-S22

25. Al-Rawi PG (2005) Near infrared spectroscopy in brain injury: today's perspective. Acta Neurochir Suppl 95:453-457 